\title{
Functional and Radiological Assessment After Preservation Rhinoplasty - A Clinical Study
}

\author{
GEORGES STERGIOU ${ }^{1 *}$, MATHIAS TREMP ${ }^{1,2 *}$, VALERIO FINOCCHI $^{3}$ and YVES SABAN ${ }^{4}$ \\ ${ }^{1}$ Praxisklinik Urania, Zurich, Switzerland; \\ ${ }^{2}$ Department of Plastic, Reconstructive, Aesthetic and Hand Surgery, \\ University Hospital Basel, University Basel, Basel, Switzerland; \\ ${ }^{3}$ Private Practice, Rome, Italy; \\ ${ }^{4}$ Private Practice, Nice, France
}

\begin{abstract}
Background/Aim: We hypothesized that improved functional outcome after preservation rhinoplasty can be validated by radiological analyses. Patients and Methods: In this retrospective study, five patients were included. Radiological assessment was evaluated by cone-beam computed tomography. Patient satisfaction regarding nasal function was evaluated by a Likert scale from 0 to $10(0=$ poor result; $10=$ very satisfied). Results: After a mean follow-up of $5 \pm 1$ months (range=4-6 months), significantly improved function was noted by all patients, with a mean Likert scale of $9.2 \pm 0.45$ (preoperative score $=2.8 \pm 0.8, p=0.0079$ ). These results are in line with the radiological results, showing an improved internal nasal valve angle (preoperative $=26.2^{\circ} \pm 1.8^{\circ}$ vs. postoperative $=32.3^{\circ} \pm 1.2^{\circ}, p=0.02$ ). Conclusion: Our study showed that besides nasal appearance, nasal function can also be dramatically improved after preservation rhinoplasty.
\end{abstract}

In recent decades, the open approach for rhinoplasty has gained wide popularity (1-3). However, the majority of reduction rhinoplasties result in destruction of the keystone area, requiring reconstruction with either spreader grafts or spreader flaps, for both aesthetic and functional reasons (4). Despite improved aesthetic and functional results, minor revision and major secondary rhinoplasties were then

This article is freely accessible online.

*These Authors contributed equally to this study.

Correspondence to: Georges Stergiou, MD, DDS, Head and Senior Consultant, Clinic for Facial, Plastic and Aesthetic Surgery, Löwenstrasse 28, 8001 Zurich, Switzerland. Tel: +41 442118260, Fax: +41 442128203, e-mail: georges.stergiou@gmail.com

Key Words: Rhinoplasty, respiratory function test, tissue preservation, patient outcome assessment, cone-beam computed tomography. frequent $(5,6)$. It has been reported that the overall complication, dissatisfaction and revision rates were $7.9 \%$, $15.4 \%$ and $9.8 \%$, respectively (7).

Today, rhinoplasty is a succession of intraoperative alternative techniques from anatomical and functional preservation to reconstruction of the nasal framework, and are not antagonist (6). Therefore, preservation rhinoplasty (PR) is considered to the next revolution in surgery and is primarily limited to reductive rhinoplasties $(1,4)$. The main principle is to replace resection with preservation, with the ultimate goal of replacing secondary rib reconstruction with minimal revision (5). Moreover, it has been reported that PR results in improved dorsal aesthetic lines with reduced dorsal irregularities and preservation of the keystone area $(4,8)$.

Modern rhinoplasty techniques may significantly improve patient quality of life in regard to nose function and appearance $(9,10)$. This requires careful preoperative analysis and planning, including radiological assessment. However, few clinical studies addressed nose function with radiological analysis after aesthetic rhinoplasty, especially after PR (11-13).

Thus, we hypothesized that PR has an improved functional outcome that can be validated by radiological analyses as reflected by the function of the internal nasal valve (INV).

\section{Patients and Methods}

In this retrospective, single-surgeon and single-centre pilot study, totally five patients (two male patients, three female patients) with a mean age of $26 \pm 8$ years (range $=19-39$ years) undergoing primary PR were included between September 2019 and December 2019. A careful clinical and endoscopic examination of the septum and nasal cavity was routinely completed in all patients. A rigid endoscope was utilized to assess septal deviation, deflection and vomerine spurs. Standard photographs, olfactory testing and 3-D computer simulations (Vectra H1 handheld system; Canfield Scientific, Parsippany, NJ, USA) were performed for all patients. Moreover, 
Table I. Patient demographics and outcomes.

\begin{tabular}{|c|c|c|c|c|c|c|c|c|c|c|}
\hline \multirow{2}{*}{$\begin{array}{l}\text { Gender/age, } \\
\text { years }\end{array}$} & \multirow[t]{2}{*}{ PDO } & \multirow[t]{2}{*}{ LDO } & \multirow[t]{2}{*}{ Turbinoplasty } & \multirow{2}{*}{$\begin{array}{l}\text { Alar base } \\
\text { reduction }\end{array}$} & \multicolumn{2}{|c|}{ INV angle } & \multicolumn{2}{|c|}{ Patient satisfaction } & \multirow[t]{2}{*}{ Complications } & \multirow{2}{*}{$\begin{array}{c}\text { Follow-up, } \\
\text { months }\end{array}$} \\
\hline & & & & & Preoperative & Postoperative & Preoperative & Postoperative & & \\
\hline $\mathrm{M} / 27$ & Yes & No & Yes & No & $28.7^{\circ}$ & $32.5^{\circ}$ & 2 & 9 & None & 6 \\
\hline $\mathrm{M} / 20$ & Yes & Yes & Yes & No & $24.5^{\circ}$ & $35.1^{\circ}$ & 2 & 10 & Hematoma & 5 \\
\hline $\mathrm{W} / 39$ & Yes & Yes & Yes & No & $24.7^{\circ}$ & $30.6^{\circ}$ & 3 & 9 & None & 4 \\
\hline $\mathrm{W} / 25$ & Yes & No & Yes & No & $25.9^{\circ}$ & $28.7^{\circ}$ & 4 & 9 & None & 4 \\
\hline W/19 & Yes & No & Yes & No & $24.7^{\circ}$ & $34.5^{\circ}$ & 3 & 9 & None & 6 \\
\hline
\end{tabular}

F: Female; M: male; PDO: push down osteotomy; LDO: let down osteotomy; INV: internal nasal valve.
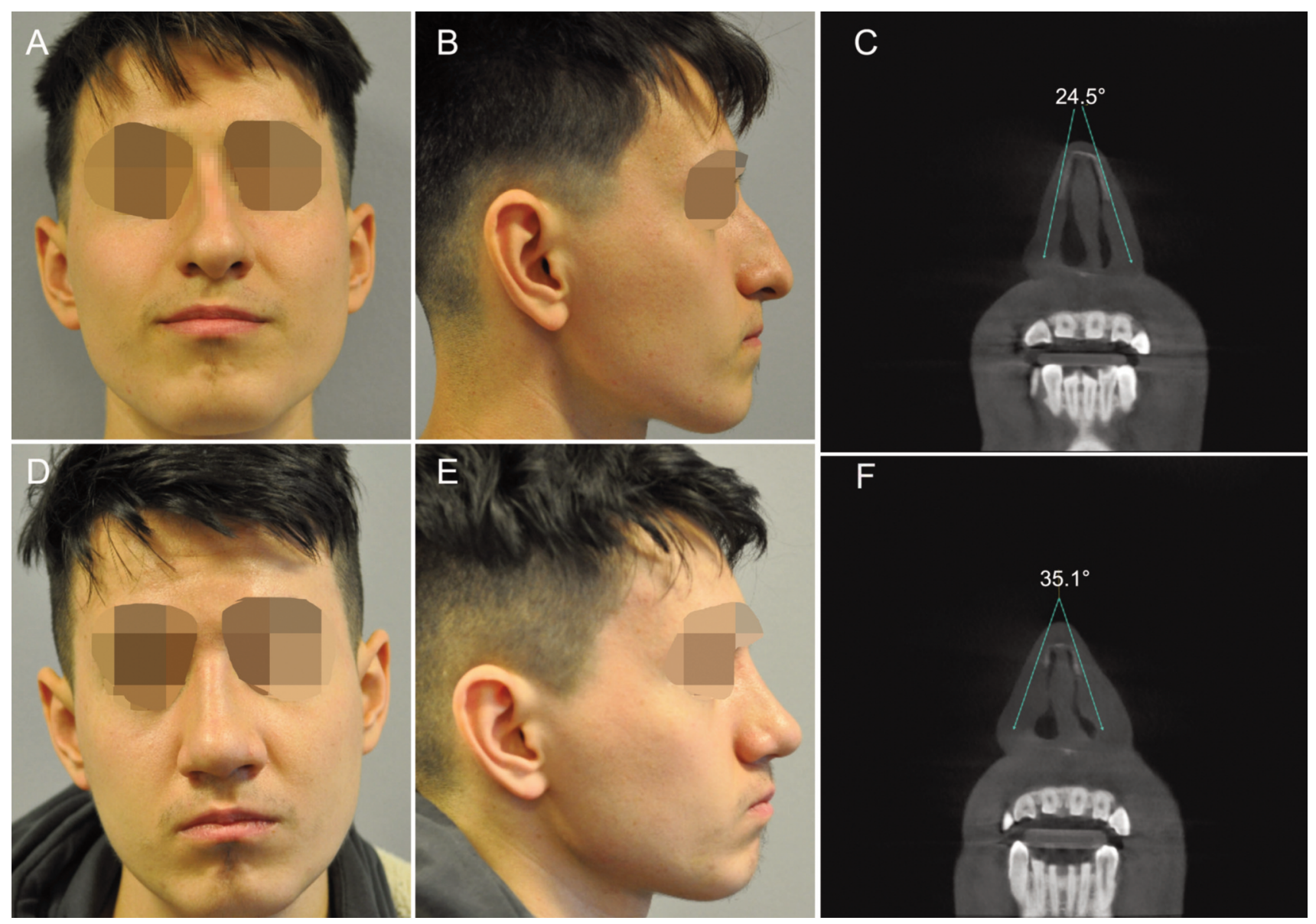

Figure 1. A 20-year-old male patient presented with macrorhinia, a droopy dip, dorsal hump with deviation, reduced nasolabial angle, and functional impairment $(A$ and $B)$. The angle of the internal nasal valve was $24.5^{\circ}$ preoperatively $(C)$. The preservation technique included turbinoplasty, resection of the vomerine spur, a hump reduction with a low septal strip, pushdown and letdown technique. After a follow-up of 3 months, a satisfactory outcome was achieved on the frontal $(D)$ and profile $(E)$ views, with an increased internal nasal valve angle $\left(35.1^{\circ}\right)(F)$ and improved function (Likert scale 10 postoperatively vs. Likert scale 2 preoperatively).

careful analysis of the nostrils was carried out regarding their size, orientation, and aesthetic landmarks.

The technique of PR was performed as previously described (7). Push-down (PD) osteotomies were performed in all cases, and let- down (LD) osteotomies (always low-to-low) were performed when more hump reduction was needed (reported to be more than $4 \mathrm{~mm}$ ) (4). Routinely, turbinoplasty was performed and bony septal deviation and vomerine spurs were resected where required and 

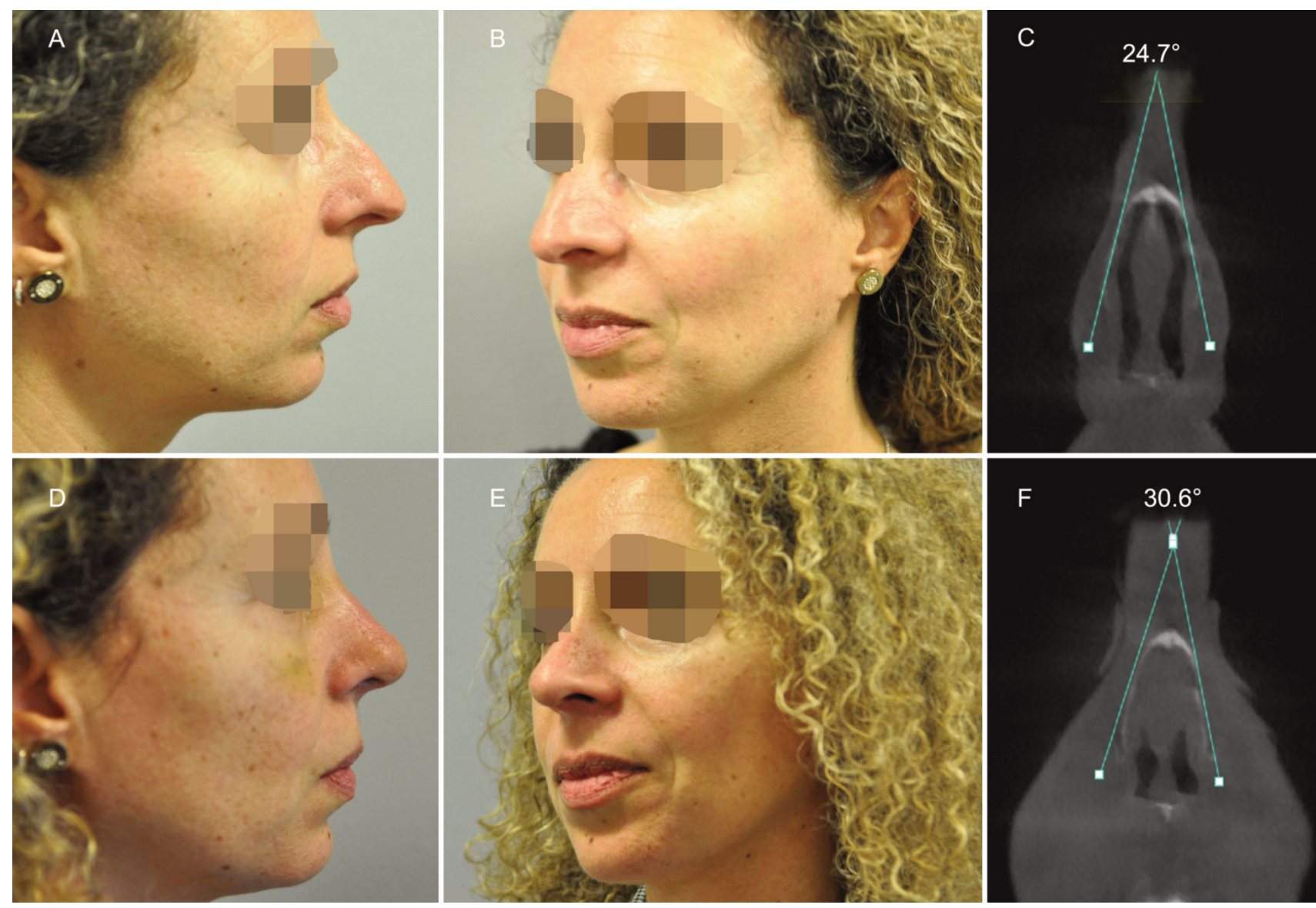

Figure 2. A 39-year-old female patient presented with macrorhinia, a tension nose, a droopy dip, dorsal hump, and functional impairment (A and B). The preservation technique included a hump reduction with a high septal strip, pushdown and letdown technique. After a follow-up of 2 months, a satisfactory outcome was achieved on the profile $(D)$ and oblique $(E)$ views, with increased internal nasal valve angle $\left(24.7^{\circ}\right.$ pre-and $30.6^{\circ}$ postoperatively) and improved function (Likert scale 3 pre- and 9 postoperatively) ( $C$ and $F$ ).

according to the preoperative cone-beam CT. For consistency, all rhinoplasties were closed using the same technique.

Outcome measures were major and minor complications, revision rate and radiological assessment of the INV pre- and postoperatively as evaluated by cone-beam computed tomography (CT). The INV has been reported to be the point of highest resistance in the nasal airway (14). The INV is a cross-sectional area bounded medially by the dorsal septum, laterally by the caudal portion of the upper lateral cartilage, and inferiorly by the head of the inferior turbinate (15, 16). This cross-sectional area was calculated by the same author and measurement was repeated to ensure precision. A modified coronal plane perpendicular to the nasal acoustic wave was created, by aligning the axial axis parallel to the bony dorsum on the sagittal view as previously described (14). Analyses of the INV dimensions were performed using byzz ${ }^{\mathrm{nxt}}$ software (orangedental GmbH \& Co. $\mathrm{KG}$, Biberach, Germany). Patient satisfaction regarding nasal function was evaluated by a Likert scale from 0 to $10(0=$ poor result; $10=$ very satisfied) preoperatively and postoperatively at final follow-up. Written informed consent was obtained from all patients, and the guidelines of the Declaration of Helsinki were followed accordingly.
Statistical analysis. The values are shown as the mean and standard deviations (SDs)/standard error of mean (SEM) or median and range where appropriate. Patient responses to nasal function and the INV measurements were compared before and after surgery using the unpaired two-tailed Student's $t$-test. Statistical significance was determined by a value of $p \leq 0.05$. The correlation between the difference of patient satisfaction and the INV before and after surgery was calculated at a 5\% level using the Pearson correlation coefficient. Analyses were performed using GraphPad Prism version 5.00 for Windows (GraphPad Software, San Diego, CA, USA).

\section{Results}

Patient demographics and outcomes are given in Table I. The mean surgery time was $120 \pm 22 \mathrm{~min}$ (range $=90-150 \mathrm{~min}$ ). After a mean follow-up of $5 \pm 1$ months (range=4-6 months), all patients healed uneventfully without significant pain or infection (Figures 1-3). One hematoma was noted, which healed conservatively. There were no revisions necessary in the follow-up period. 

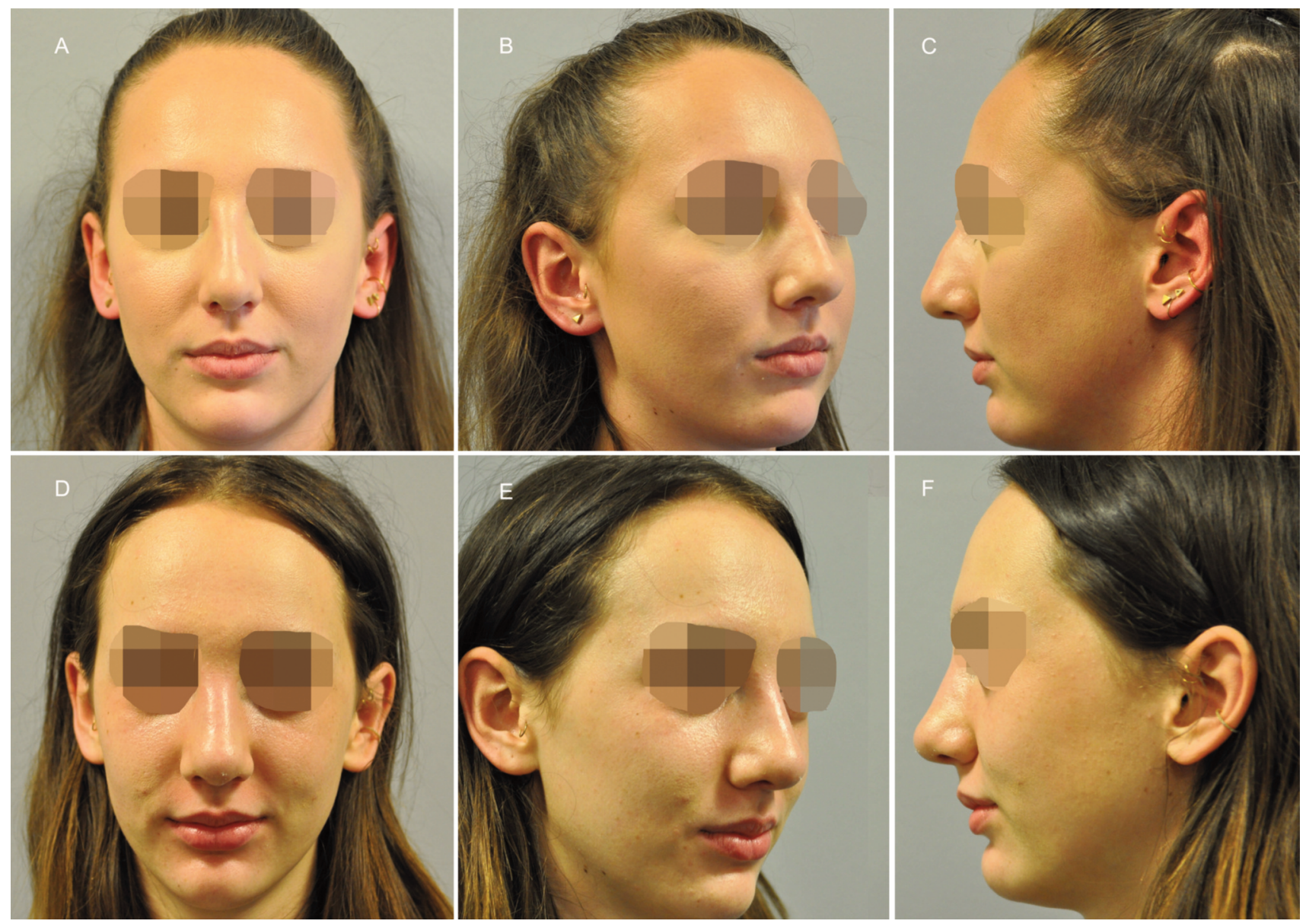

Figure 3. A 19-year-old female patient presented with a bulbous tip, dorsal hump, reduced nasolabial angle, and breathing difficulties (A-C). The preservation technique included turbinoplasty, resection of the vomerine spur, a hump reduction with a high dorsal strip, pushdown technique, a cephalic resection, transdomal suture, dome equalization suture and columellar strut. After a follow-up of 3 months, a satisfactory outcome was achieved (D-F) with increased nasal internal valve angle (24.7 $7^{\circ}$ pre- and $34.5^{\circ}$ postoperatively) and improved function (Likert scale 3 pre-and 9 postoperatively).

An improved nasal function was noted by all patients, with a mean Likert scale of $9.2 \pm 0.45$ at final follow-up (preoperative score $2.8 \pm 0.8, p=0.0079$. These results are in line with the radiological results, showing a widening of the narrowest portion of the nasal cavity (preoperative INV $26.2^{\circ} \pm 1.8^{\circ} \mathrm{vs}$. postoperative INV $32.3^{\circ} \pm 1.2^{\circ}, p=0.02$. Interestingly, we found a higher difference of the INV when PD osteotomy was combined with LD osteotomy compared to use of PD osteotomy alone, which was also in line with a high patient satisfaction. Moreover, we found a strong linear relationship between the difference of functional outcome as assessed by the patient, and the difference of the INV as assessed by the conebeam CT pre- and postoperatively ( $\mathrm{r}=0.73, p=0.02$, Figure 4$)$.

\section{Discussion}

To the best of our knowledge, this is the first clinical study to evaluate the impact of PR on INV dimensions objectively in patients using a validated radiological methodology. In a recent study by Abdelwahab et al., the impact of different hump takedown techniques, namely conventional hump resection with midvault reconstruction, $\mathrm{PD}$ and LD procedures, on the INV dimensions was evaluated in a cadaveric study (14). They found that neither conventional hump resection nor LD dorsal $\mathrm{PR}$ technique reduced the INV dimensions. However, the PD preservation technique significantly reduced the INV dimensions (14). Our study results are in line with these: We confirmed a significant improvement of nasal function after PR as evaluated in our study by a 10-point Likert scale. It has been shown that this method of measuring satisfaction has good validity and reliability and can be used in clinical trials due to the ease of administration and interpretation (17). Subjective patient satisfaction was in line with our radiological analyses. Those results concur with previous reports, showing a correlation between the INV cross-sectional area and 


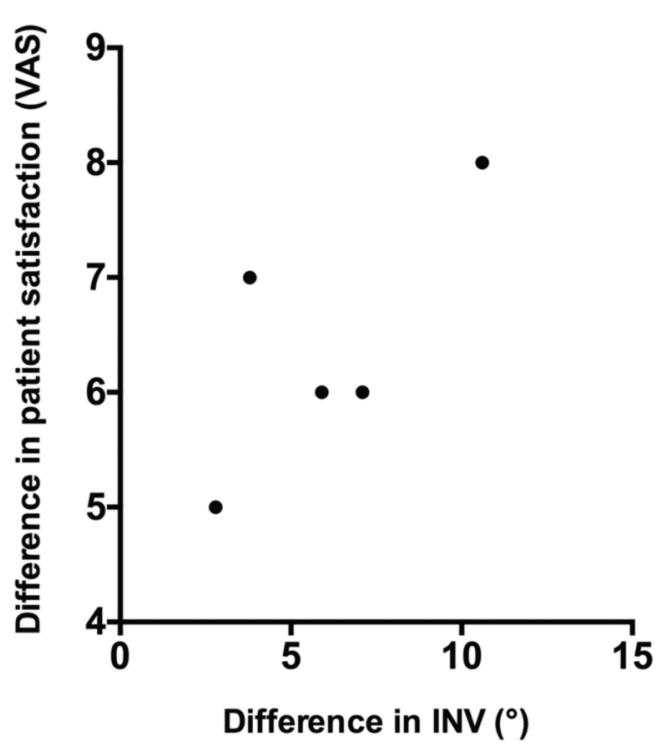

Figure 4. Pre- and postoperative assessment showed improved nasal function as evaluated by the patient using the Visual Analogue Scale (VAS). There was a strong linear relationship between the difference of the functional outcome as assessed by the patient, and the difference of the internal nasal valve (INV/angle as assessed by the cone-beam CT pre- and postoperatively $(r=0.73, p=0.02)$.

postoperative patient satisfaction $(18,19)$. In line with Abdelwahab et al., (14) we hypothesize that double osteotomy, and LD osteotomy seem to positively affect nose function by opening the INV. We found a higher difference of the INV dimensions when PD osteotomy was combined with LD osteotomy compared to PD osteotomy alone. Consequently, nostril flaring may occur, and seal/alar base reduction should be considered in such cases.

The LD operation consists of a high septal resection, followed by resection of a portion of the ascending frontal process of the maxilla $(4,20)$. Subsequent downward positioning of the bony vault onto the frontal process of the maxilla is performed, opening the INV. Conversely, the PD technique consists of downward impaction of the fully mobilized nasal pyramid, and is applied in patients with smaller humps $(<4 \mathrm{~mm})$ (4). A high septal resection is performed, followed by lateral and transverse osteotomies. The result is a de-projection of the tip with elongation of the nose, and a subsequent impaction of the bony vault downward into the pyriform aperture $(4,20)$.

The fundamental goal of the PD technique is to preserve both the keystone area and the continuity of the cartilaginous vault. This conservative approach has a minimal downtime, avoids nasal valve collapse, with positive effects on respiration, and preserves the dorsal aesthetic lines. In addition, lowering the intact cartilaginous vault during the PD technique produces a vertical vector downwards on the scroll area junction between the upper and lower lateral cartilages, which in turn causes a cephalic rotation of the latter (4).

Another inherent advantage of the dorsal preservation technique is that there is no need for spreader grafts (4). Transversally, the upper lateral cartilages act like springs and open the INV. Longitudinally, the lowering of the upper lateral cartilages modify the scroll area, which is untouched during the procedure (21). Consequently, a definite improvement in nasal respiration was recently reported by 309 patients who underwent dorsal PR (4). It has been reported that this persistence of improved respiration is in direct contrast to resection rhinoplasty, in which the quality of respiration tends to deteriorate with time because of age-related thinning and retraction of the surgically altered musculocutaneous layer overlying the modified cartilaginous dorsum (4).

Aesthetic rhinoplasty carries the real risk of patient dissatisfaction and request for revision (7). Therefore, the revision rate should be kept to a minimum, and the technique should give consistent and reliable results, with the ultimate goal of achieving high patient satisfaction and adequate nasal function. Published revision rates range from $5 \%$ for tip rhinoplasty to $15.5 \%$ for large series of secondary rhinoplasties (22), whereas complication rates range from $5 \%$ to $18.6 \%$ (23), with an overall satisfaction rate $83.6 \%$ (24). Conversely, the revision rate in PR has been reported to be around $8 \%$ (4). Ishida et al. reported a partial hump recurrence of $15 \%$ in 120 patients who underwent conservative rhinoplasty, caused by the difficulty in determining and quantifying the size of the septal strip that should be resected, and the consequence of the memory of the soft tissues (25). It has been suggested that scoring the resting upper part of the septum immediately below the keystone area, performing lateral keystone dissection and preferring the LD procedure for kyphotic noses may prevent hump relapse (8).

Besides the cosmetic appearance, the functional outcome remains of paramount importance and there is an intricate interplay between form and function. Bony septal deviation and vomerine spurs should be resected as necessary to improve respiration (4). Functionally, the competence of the INV should be preserved and all valves should be opened through the enlargement of the nasal base and its reorientation following the rotation processes.

Our study has several limitations, such as a limited sample size with a limited follow-up, a lack of homogeneity, and its retrospective design. Thus, longitudinal and multicenter studies are needed with a long-term follow-up including objective measurements such as rhinomanometry and validated subjective patient reported outcome measures (4, 26). It has been reported that rhinomanometry and acoustic rhinometry are reliable and objective methods of determining functional and geometric changes in the nasal cavity after Le 
Fort I osteotomy (27). However, it has also been shown that there is a poor correlation between acoustic rhinometry and measures of the INV angle, and between acoustic rhinometry and subjective symptoms $(28,29)$.

In conclusion, PR is the next revolution in rhinoplasty, with less postoperative morbidity and revisions far simpler when compared to conventional techniques. Our preliminary results show that besides nasal appearance, function can also be dramatically improved by this technique, and this can be verified by radiological analyses.

\section{Conflicts of Interest}

The Authors declare that they have no conflicts of interest. None of the Authors has a financial interest in any of the products, devices, or drugs mentioned in this article.

\section{Authors' Contributions}

Study design: Georges Stergiou, Mathias Tremp, Yves Saban, Valerio Finocchi; Data acquisition and collection: Georges Stergiou, Mathias Tremp; Manuscript drafting: Mathias Tremp, Georges Stergiou; Critical revision: all Authors. Final approval: all Authors

\section{References}

1 Rohrich RJ and Afrooz PN: Primary open rhinoplasty. Plast Reconstr Surg 144(1): 102e-117e, 2019. PMID: 31246835. DOI: 10.1097/PRS.0000000000005778

2 Rohrich RJ and Afrooz PN: Rhinoplasty refinements: The role of the open approach. Plast Reconstr Surg 140(4): 716-719, 2017. PMID: 28953724. DOI: 10.1097/PRS.0000000000003743

3 Gunter JP and Rohrich RJ: External approach for secondary rhinoplasty. Plast Reconstr Surg 80(2): 161-174, 1987. PMID: 3602167. DOI: 10.1097/00006534-198708000-00001

4 Saban Y, Daniel RK, Polselli R, Trapasso M and Palhazi P: Dorsal preservation: The push down technique reassessed. Aesthet Surg J 38(2): 117-131, 2018.

5 Daniel RK: The preservation rhinoplasty: A new rhinoplasty revolution. Aesthet Surg J 38(2): 228-229, 2018. PMID: 29319787. DOI: $10.1093 /$ asj/sjx 180

6 Saban Y: Rhinoplasty: Lessons from "errors" : From anatomy and experience to the concept of sequential primary rhinoplasty. HNO 66(1): 15-25, 2018. PMID: 29322251. DOI: 10.1007/ s00106-017-0454-5

7 Neaman KC, Boettcher AK, Do VH, Mulder C, Baca M, Renucci JD and VanderWoude DL: Cosmetic rhinoplasty: Revision rates revisited. Aesthet Surg J 33(1): 31-37, 2013. PMID: 23277618. DOI: 10.1177/1090820X12469221

8 Tuncel U and Aydogdu O: The probable reasons of dorsal hump problems following let-down/push-down rhinoplasty and solution proposals. Plast Reconstr Surg 144(3): 378e-385e, 2019. PMID: 31461007. DOI: 10.1097/PRS .0000000000005909

9 Saleh AM, Younes A and Friedman O: Cosmetics and function: Quality-of-life changes after rhinoplasty surgery. Laryngoscope 122(2): 254-259, 2012. PMID: 22252921. DOI: 10.1002/lary. 22390
10 Santos M, Rego AR, Coutinho M, Sousa CAE and Ferreira MG: Spare roof technique in reduction rhinoplasty: Prospective study of the first one hundred patients. Laryngoscope 129(12): 27022706, 2019. PMID: 30628092. DOI: 10.1002/lary.27804

11 Pousti SB, Touisserkani S, Jalessi M, Kamrava SK, Sadigh N, Heshmatzade Behzadi A and Arvin A: Does cosmetic rhinoplasty affect nose function? ISRN Otolaryngol 2011: 615047, 2011. PMID: 23724256. DOI: 10.5402/2011/615047

12 Constantinides MS, Adamson PA and Cole P: The long-term effects of open cosmetic septorhinoplasty on nasal air flow. Arch Otolaryngol Head Neck Surg 122(1): 41-45, 1996. PMID: 8554745. DOI: 10.1001/archotol.1996.01890130035005

13 McKee GJ, O'Neill G, Roberts C and Lesser TH: Nasal airflow after septorhinoplasty. Clin Otolaryngol Allied Sci 19(3): 254257, 1994. PMID: 7923851. DOI: 10.1111/j.1365-2273. 1994.tb01226.x

14 Abdelwahab MA, Neves CA, Patel PN and Most SP: Impact of dorsal preservation rhinoplasty versus dorsal hump resection on the internal nasal valve: A quantitative radiological study. Aesthetic Plast Surg, 2020. PMID: 32016500. DOI: 10.1007/ s00266-020-01627-z

15 Takhar A, Stephens J, Randhawa PS, Poirrier AL and Andrews P: Validation of the Sino-Nasal Outcome Test-23 in septorhinoplasty surgery. Rhinology 52(4): 301-304, 2014. PMID: 25479209. DOI: 10.4193/Rhin14.009

16 Patel B, Virk JS, Randhawa PS and Andrews PJ: The internal nasal valve: A validated grading system and operative guide. Eur Arch Otorhinolaryngol 275(11): 2739-2744, 2018. PMID: 30293091. DOI: 10.1007/s00405-018-5142-x

17 Tremp M, Wettstein R, Tchang LA, Schaefer DJ, Rieger UM and Kalbermatten DF: Power-assisted liposuction (PAL) of multiple symmetric lipomatosis (msl)-a longitudinal study. Surg Obes Relat Dis 11(1): 155-160, 2015. PMID: 25393046. DOI: 10.1016/j.soard.2014.05.004

18 Sipila $J$ and Suonpaa J: A prospective study using rhinomanometry and patient clinical satisfaction to determine if objective measurements of nasal airway resistance can improve the quality of septoplasty. Eur Arch Otorhinolaryngol 254(8): 387-390, 1997. PMID: 9332895. DOI: $10.1007 /$ bf0 1642556

19 Stewart MG and Smith TL: Objective versus subjective outcomes assessment in rhinology. Am J Rhinol 19(5): 529-535, 2005. PMID: 16270610.

20 Tremp M, Haack S, Mijuskovic B and Haug M: Suture techniques and cartilage grafts in nasal tip surgery: An algorithm in primary and secondary rhinoplasty. J Plast Reconstr Aesthet Surg 73(3): 563-570, 2019. PMID: 31668523. DOI: 10.1016/j.bjps.2019.09.023

21 Gola R: Functional and esthetic rhinoplasty. Aesthetic Plast Surg 27(5): 390-396, 2003. PMID: 14727080. DOI: 10.1007/s00266003-2136-9

22 Bateman N and Jones NS: Retrospective review of augmentation rhinoplasties using autologous cartilage grafts. J Laryngol Otol 114(7): 514-518, 2000. PMID: 10992932. DOI: 10.1258/ 0022215001906264

23 Deva AK, Merten S and Chang L: Silicone in nasal augmentation rhinoplasty: A decade of clinical experience. Plast Reconstr Surg 102(4): 1230-1237, 1998. PMID: 9734450. DOI: 10.1097/00006534-199809040-00052

24 Khansa I, Khansa L and Pearson GD: Patient satisfaction after rhinoplasty: A social media analysis. Aesthet Surg J 36(1): NP15, 2016. PMID: 26063834 DOI: 10.1093/asj/sjv095 
25 Ishida J, Ishida LC, Ishida LH, Vieira JC and Ferreira MC: Treatment of the nasal hump with preservation of the cartilaginous framework. Plast Reconstr Surg 103(6): 17291733; discussion 1734-1725, 1999. PMID: 10323714

26 Barone M, Cogliandro A, Salzillo R, Colapietra A, Alessandri Bonetti M, Morelli Coppola M, List E, Ciarrocchi S, Tenna S and Persichetti P: Role of spreader flaps in rhinoplasty: Analysis of patients undergoing correction for severe septal deviation with long-term follow-up. Aesthetic Plast Surg 43(4): 1006-1013, 2019. PMID: 30868305. DOI: 10.1007/s00266-019-01343-3

27 Haarmann S, Budihardja AS, Wolff KD and Wangerin K: Changes in acoustic airway profiles and nasal airway resistance after le fort i osteotomy and functional rhinosurgery: A prospective study. Int J Oral Maxillofac Surg 38(4): 321-325, 2009. PMID: 19233618. DOI: 10.1016/j.ijom.2009.01.006
28 Isaac A, Major M, Witmans M, Alrajhi Y, Flores-Mir C, Major P, Alsufyani N, Korayem M and El-Hakim H: Correlations between acoustic rhinometry, subjective symptoms, and endoscopic findings in symptomatic children with nasal obstruction. JAMA Otolaryngol Head Neck Surg 141(6): 550555, 2015. PMID: 25856660. DOI: 10.1001/jamaoto.2015.0468

29 Miman MC, Deliktas H, Ozturan O, Toplu Y and Akarcay M: Internal nasal valve: Revisited with objective facts. Otolaryngol Head Neck Surg 134(1): 41-47, 2006. PMID: 16399179. DOI: 10.1016/j.otohns.2005.08.027

Received April 18, 2020

Revised April 29, 2020

Accepted May 4, 2020 